\title{
Improving academic literacy by teaching collocations
}

\section{Déogratias Nizonkiza}

School of Languages, North-West University (Potchefstroom Campus), South Africa; English Language Learning and Acquisition (ELLA) Department, Douglas College, Canada

E-mail: deo.nizonkiza@nwu.ac.za; nizonkizad@douglascollege.ca

\begin{abstract}
This study explores the effect of teaching collocations on building academic vocabulary and hence improving academic writing abilities. A pre-/post-test experimental design was used to analyse collocations produced in two tasks completed by the study's participants, English majors at a university in Burundi. They were presented with a completion task and an essaywriting task before and after being exposed to a collocation-based syllabus. The syllabus was designed by selecting target words from the Academic Word List (AWL) (Coxhead 2000) and collocations from the Oxford Collocations Dictionary for Students of English (Crowther, Dignen, and Lea 2002). The awareness-raising approach (cf. Barfield 2009) and an adapted version of McCarthy and O'Dell's (2005) collocation web model were the techniques adopted for teaching collocations. The results show that participants performed significantly better on the post-test than on the pre-test in their production of collocations in both tasks. This suggests that an intervention contributes towards building students' productive use of collocations in both cued recall and essay writing, supporting earlier findings (cf. Barfield 2009, Seesink 2007). In light of these findings, pedagogical consequences and avenues for improving higher education students' use of collocations in writing are discussed.
\end{abstract}

Keywords: teaching collocations, productive knowledge of collocations, academic literacy, academic word list, collocation web model

\section{Introduction}

The question of academic success has compelled higher education institutions worldwide to test students entering universities (cf. Scholtz 2012). The main objective of this practice is to assess students' preparedness to meet the challenges posed in higher education institutions (Scholtz 2012, Van Dyk 2005, Van Dyk and Van de Poel 2013, Weideman 2006). This preparedness can be roughly referred to as "academic literacy", a concept that has been explored from different angles (cf. Van Dyk and Van de Poel 2013). The latest review of the available literature regarding this concept can be found in Van Dyk and Van de Poel (2013). These scholars, supporting Cliff and Yeld's (2006) earlier observation, suggest that the skills and knowledge needed to achieve academic goals are the key elements according to which academic literacy should be defined. Academic literacy, or rather academic literacies-which is an 
increasing trend today (Butler 2013) — should also be examined within local contexts and environments, as different institutions may have different practices/requirements. These practices and requirements may vary across disciplines (Butler 2013, Van Dyk and Van de Poel 2013) and also change over time (Van Dyk and Van de Poel 2013).

It may rightly be argued that language is by no means the sole factor that is a matter of concern regarding academic performance at universities. However, it is also fair to say that language is widely "regarded as one of the most important issues" in this regard (Van Rooy and CoetzeeVan Rooy 2015:31). This observation supports Van de Poel and Van Dyk's (2014) earlier observation, which considers students' linguistic abilities to be an important dimension of academic literacy. It is therefore not surprising to see that students' language skills are tested as a means of gauging their preparedness to follow lectures and meet other academic demands. Language skills are thus taken to be one predictor of academic success. This may account for the traditional association between academic literacy and reading and writing skills, which have been considered as academic literacy's main components for quite some time (Kostogriz and Godley 2007).

However, scholars have rightly observed that academic literacy goes beyond the ability to read and write. This is exemplified in the more recent trends mentioned above, which suggest considering local contexts as well as different disciplines as key elements for defining academic literacy/literacies. This study adheres to the dimensional approach to academic literacy outlined in Van Dyk and Van de Poel's (2013) definition, which distinguishes between "three different dimensions: a social (exchange information), cognitive (understand, organise and reason about information) as well as a linguistic (language) dimension" (cf. also Nizonkiza and Van Dyk (2015:152). More specifically, the linguistic dimension of academic literacy and writing skills in particular are relevant for this study. The latter requires mastery of vocabulary, the lack of which "is what makes writing in a foreign language difficult" (Nadarajan 2011:184). The importance of vocabulary has been stressed, and some scholars argue that "vocabulary proficiency is probably the best indicator of overall text quality" (Nadarajan 2011:184). I will return to this importance in section 2 .

Academic literacy has been measured by means of different tests. These test results "are generally used for admission and placement purposes and to determine academic support and interventions" (Scholtz 2012:48). The available literature indicates that academic literacy is a global issue, but the South African case deserves a special mention. Most South African higher education institutions systematically measure first-year students' academic literacy and thereafter suggest intervention programmes tailored to students' needs. While measuring academic literacy in a South African context goes beyond language proficiency, the latter seems to be the only matter of concern in some Northern American institutions. For example, students applying to study at McGill University in Canada have to prove their proficiency in English by means of one of the following tests ${ }^{1}$ : The Canadian Academic English Language (CAEL), the Test of English as Foreign Language (TOEFL), the International English Language Testing System (IELTS), the Cambridge Certificate of Proficiency in English (CPE), the Cambridge Certificate in Advanced English (CAE), the University of Michigan English Language Test (MELAB), etc. These tests target students whose mother tongue is not English, which is not necessarily the case in a South African context. The Test of Academic Literacy Levels

\footnotetext{
${ }^{1}$ Information retrieved from: http://www.mcgill.ca/gradapplicants/international/apply/proficiency. Accessed on 18 September 2016.
} 
(TALL), which is in English, has its Afrikaans counterpart, Toets van Akademiese Geletterdheidsvlakke (TAG). This test and the National Benchmark Test (NBT) appear to be the two most widely used tests (Nizonkiza and Van Dyk 2015). Based on the above, the South African context may be a good example of efforts channelled into these attempts to address the issue of academic literacy. South African practices could thus inspire many other sub-Saharan countries such as Burundi, where academic literacy is an issue, but is simply overlooked.

However, it is important to note that all the tests used in South Africa appear to be based on roughly the same construct or definition of "academic literacy" (Scholtz 2012, Weideman 2006). Van Dyk and Weideman (2004) summarise the latter in competencies, i.e. a range of activities in which students should engage for their academic success. This is what Butler (2013) refers to as a "skill-based" or "functional-oriented" approach to academic literacy. According to Van Dyk and Weideman (2004:10), some of these activities include:

understanding a range of academic vocabulary in context; interpreting and using metaphor and idiom, and perceiving connotation, word play and ambiguity; understanding relations between different parts of a text, being aware of the logical development of (an academic) text, via introductions to conclusions, and knowing how to use language that serves to make the different parts of a text hang together. ${ }^{2}$

These activities are what university entrants are expected to be capable of in order to be able to meet the enormous challenges the academic environment may present them with. Addressing such challenges remains a huge issue. Here, suffice it to say that many scholars worldwide have attempted to develop intervention courses aimed at improving students' academic literacy and thus enhancing their academic success (e.g., Weideman 2007, Van der Walt 2011). Building and improving academic vocabulary is indeed important for higher education students (Coxhead 2000; Nadarajan 2011; Nation 2001, 2006; Weideman 2007). While these intervention courses propose activities that help teach academic literacy, they seem to overlook collocations, which constitute an important component of academic writing (e.g., Gledhill 2000, Laufer and Waldman 2011, Nesselhauf 2005).

Collocations are combinations such as tell lies, heavy rain, and deeply religious (Boers, Demecheleer, Coxhead, and Webb 2014:55). They are "conventionalized, recurring word combinations" (Gyllstad 2007:1) and are the result of native speakers' preferences (Pawley and Syder 1983). Various definitions of collocations have been proposed, but the co-occurrence of words is the main idea contained in all of them. Lewis's (1997:8) definition of collocations as "...the readily observable phenomenon whereby certain words co-occur in natural text with greater than random frequency" places emphasis on the notions of co-occurrence and frequency. This entails that for co-occurring words to qualify as a collocation, they have to appear together frequently. Appearing together of course does not necessarily mean that the words follow each other. There may be a few intervening words, as stressed in Sinclair's (1991:170) definition that collocations are "the occurrence of two or more words within a short space of each other in a text". In Sinclair's terms, this space is referred to as "span", while the co-occurring words are the "node" and the "collocate", respectively the main word and the cooccurring one. In the sentence They carried out an in-depth analysis of the results ${ }^{3}$, carry out

\footnotetext{
${ }^{2}$ These activities are described in Van Dyk and Weideman (2004:16-17), where their exhaustive list can be found.

${ }^{3}$ Example retrieved from an online collocation dictionary at: http://www.ozdic.com/collocationdictionary/analysis (Accessed 15 April 2013).
} 
co-occurs with analysis (in a verb + noun combination) in a span of three words. Analysis is the node, while carry out is the co-occurring word or the collocate. However, in the case of indepth analysis, which is an adjective + noun collocation, in-depth and analysis follow each other.

Readers are referred to Gyllstad (2007) for a detailed classification of collocations and a description of how they have been approached. Here, I would like to point out that collocations have proven to be useful at the productive level ${ }^{4}$ especially (cf. Boers, Eyckmans, Kappel, Stengers and Demecheleer 2006, Bonk 2001, Howarth 1998, Paquot 2008, Schmitt 1998). Collocations also characterise academic writing (Gledhill 2000, Li and Schmitt 2009, Paquot 2008). Furthermore, research evidence shows that collocations still cause problems for both English as a Second Language (ESL) and English as a Foreign Language (EFL) learners, even at advanced levels (Gouverneur 2008, Jaén 2007, Laufer and Waldman 2011, Nesselhauf 2005), and that many collocation errors occur in written production (Eyckmans 2009, Nesselhauf 2005).

As already mentioned, most academic literacy modules do not seem to pay any attention to collocations. Therefore, the fundamental question worth raising is whether collocations should be focused on while teaching academic literacy. Taking into account the widely accepted importance of collocations and their difficult nature, as well as the voices increasingly calling for teaching them explicitly in EFL and ESL contexts ${ }^{5}$, this study is an attempt to teach collocations of words pertaining to the Academic Word List (AWL).

As described in Coxhead (2000), the AWL consists of words frequent in academic environments and was compiled in order to prepare students for higher education studies. It contains 570 word families that are categorised in 9 sub-lists of 60 words each and a $10^{\text {th }}$ that consists of 30 words. Word families are words and their family members, which can be derivations and inflections of a headword. For example, the first word of the first sub-list is analyse. Its members are analyse, analysed, analyser, analysers, analyses, analysing, analysis, analyst, analysts, analytic, analytical, analytically, analyze, analyzed, analyses, and analysing. It should be noted here that the difference in spelling between British and American English is considered, and words with a different spelling such as analyse and analyze are all included as members of the same family. The sub-lists contain the most frequent members of the families. This entails that the first sub-list contains the 60 most frequent words, while the second contains the 60 next most frequent words, etc. This was done for teaching and learning purposes.

To date, the AWL has been the academic vocabulary list most widely used/referred to (cf. Coxhead 2011, Durrant 2009, Nation 2001, Schmitt and Schmitt 2005). It has been influential in testing, teaching, and designing materials to teach for academic purposes (Coxhead 2011, Durrant 2014, Hyland and Tse 2007). A general observation is that these words may be particularly difficult for ESL and EFL students because they are not frequent enough to be part

\footnotetext{
${ }^{4}$ Laufer (1998:257) identifies three levels of word knowledge: receptive knowledge is understanding the most frequent and core meaning of a word, e g solution as in solution of a problem rather than chemical solution. Controlled productive knowledge entails producing words when prompted by a task. An example is having to complete the word fragrant in the garden was full of fra-flowers. Free productive knowledge has to do with the use of words at one's free will, without any specific prompts for particular words, as in the case of free composition.

${ }^{5}$ English should not be the only language in which collocations matter, but most of the studies currently available in the literature focus on this language.
} 
of the common/general vocabulary that can be learned implicitly; nor are they specific enough to be taught as part of the technical vocabulary of the core subject courses (Coxhead 2000, Nation 2001). These are the reasons that the AWL words have been chosen for this study. In addition, one of the most important aspects of productive knowledge is collocations, which have proven to cause more problems in production than in comprehension (Eyckmans 2009, Nesselhauf 2005, Nizonkiza 2016). The following questions guide the study: (i) to what extent does explicitly teaching collocations pertaining to the AWL contribute to building academic vocabulary?, and (ii) does the teaching of collocations of words from the AWL result in the efficient use of collocations in writing?

Furthermore, it should be noted that, irrespective of its popularity for teaching and research purposes, very few attempts have been made to teach collocations of the AWL words. To my knowledge, only Seesink (2007) has investigated the role that teaching academic vocabulary, particularly collocations from the AWL, could play in ESL writing development. She examined the second question investigated in the present study. Her study showed that focusing on academic vocabulary indeed helps ESL learners use collocations. Learners performed well on the collocation test she presented to participants at the end of a course aimed at raising students' awareness of collocations. Moreover, the writing samples produced at three different points during the investigation show that students produced correct collocations in their writing. However, while it can be assumed that this is the result of having explicitly taught collocations, it raises the question of the extent to which teaching really contributed, as participants were not pre-tested. The present study intends to complement her study: it extends the research to EFL students, and adopts a more controlled approach by using a pre-/post-test design for a completion and an essay-writing task (see section 3.3). Approaches to teaching collocations available in the literature are the subject of the next section.

\section{Approaches to teaching collocations}

Collocations have captured the attention of second-language (L2) and foreign-language (FL) practitioners and researchers over the past decades (cf. Barfield and Gyllstad 2009). Among other things, the question of how best to teach collocations has been raised (cf. Lewis, 1993, 1997, 2000; Meunier and Granger 2008; Webb and Kagimoto 2011). This question follows from the observation that collocations are important in L2 and FL contexts (Pawley and Syder 1983; Wray 2000, 2002) but are also extremely difficult for L2 and FL learners (cf. Gouverneur 2008; Jaén 2007; Laufer and Waldman 2011; Nesselhauf 2005; Webb and Kagimoto 2011). The teaching practices that have been adopted so far vary considerably. In their appraisal of these practices, Boers et al. (2014) identify four popular formats: 'connect', 'insert' the verb, 'underline' the verb, and 'insert the collocation'. Boer et al. (2014) tested these formats in substudies involving verb-noun collocations.

The connect format presents verbs in one column (left) and nouns in another column (right) and students are instructed to match them. This is intended to draw students' attention to assembling the collocation from its constituents. However, this approach can be criticised, for it prompts learners "to assemble collocations from distinct building blocks rather than being stimulated to process the collocations as intact wholes from the start" (Boers et al. 2014:58). Boers et al. (2014) base their criticism on Lewis's (2000:132) suggestion that "[t]he first task of the language teacher is to ensure that they (collocations - DN) are not unnecessarily taken apart". 
Furthermore, this type of exercise can lead students to guess, especially if they are not familiar with most of the collocations they have to choose from (Boers et al. 2014).

The second and third formats, 'insert' and 'underline' the verb respectively, use the matching technique. The second format is "contextualized matching", which presents students with gapped sentences which they have to fill in using the verbs provided. Such a format adopts a matching technique, since choosing the right verb requires the student to know and infer from the meaning of the noun in its context of use. Its advantage is obviously that it presents more (sentential) context than the 'connect' format and targets the verb, which is the part that students often miss (Boers et al. 2014). This also holds true for the 'underline' the verb format, which places the verbs to choose from next to each other in the sentence and has the student underline the appropriate verb. Both formats present the collocation in a sentential context, but as convincingly argued by Boers et al. (2014), if the students are not familiar with the collocations in question, the exercises may end up being a guessing game, just like the 'connect' format.

The 'insert a collocation' format is the fourth popular format tested by Boers et al. (2014). This type of exercise requires the student to insert the whole collocation. While the context is basically the same as in the 'insert' and 'underline' the verb formats, this task differs fundamentally from those formats. It "appears more in accordance with the psycholinguistics literature, which suggests that the processing advantages afforded by formulaic language stem from a 'holistic' representation of formulaic sequences in memory" (Boers et al. 2014:60), which gives this format an advantage over the other formats discussed so far. Boers et al. (2014) also identify two other popular approaches. They did not test these in their study, as they direct students' attention to the wrong collocation, and thus to what should not be remembered. These approaches are referred to as 'correct the wrong collocations' and 'odd one out'.

Boers et al. (2014) assume that the 'insert the collocation' format may yield better retention of verb-noun collocations than the other three formats, i.e. 'connect', 'insert' the verb, and 'underline' the verb. The results from their studies (four trials) indicate that gains were small in all the conditions with no significant differences resulting, contrary to what had been initially assumed. 'Insert the collocation' was, however, found to have the potential to bring about more gains in a replication study by Boers, Dang, and Brian (2016).

Boers et al. (2014) can be given credit for comparing two fundamentally different approaches, which represent two emerging approaches to teaching vocabulary. Traditionally associated with grammar, explicit and implicit knowledge has recently been extended to lexical knowledge, and the relationship between them "has only begun to be investigated" (Sonbul and Schmitt 2013:122). 'Connect', 'insert' the verb, and 'underline' the verb are explicit in nature, while 'insert the collocation' is implicit.

The explicit-implicit line seems to be the axis along which many studies have attempted to teach collocations. This includes Webb and Kagimoto $(2009,2011)$, who explored the effect of explicitly teaching collocations with a focus on the nature of the tasks (receptive vs. productive). In their 2009 study, they tested the effect of receptive and productive tasks on collocation growth. The results indicate that the explicit teaching of collocations results in significant gains in collocation growth, both receptively and productively. 
Boers, Lindstromberg and Eyckmans (2012) and Sonbul and Schmitt (2013) compared explicit and implicit approaches to teaching collocations and examined their effect on collocation development. Boers et al. (2012) tested the effect of explicit teaching on fostering collocation growth by repeating some of the experiments reported on in Boers and Lindstromberg (2008a, 2008b). The latter studies showed that phonological patterns such as alliteration (green grass) and assonance (home phone) contribute to collocation retention. As opposed to the original studies, which confirmed the role of alliteration and assonance, Boers et al. (2012) used the same words without explicitly directing students' attention to the phonological patterns. The task used was a dictation, after which participants were asked to produce the words they could remember. As reported in their study, the participants recalled many of the words, but not as many as in the original studies, which confirms the advantage of explicit teaching. The importance of explicit teaching was confirmed in Sonbul and Schmitt's (2013) study. Their study involved both native and non-native speakers who were tested before and after the treatments (explicit teaching on the one and implicit on the other). The results from this study reveal indeed that explicit teaching resulted in long-term gains for both groups of participants while implicit teaching did not. These studies fall into the category of works with a psycholinguistic approach to the teaching of collocations championed by Boers and Lindstromberg (2008a, 2008b).

In line with the psycholinguistic approach to teaching collocations, Durrant and Schmitt (2010) tested Wray's (2002) claim that non-native speakers adopt a non-formulaic approach to language learning. This entails that unlike native speakers who chunk words in their learning, thus adopting a formulaic approach to learning (cf. Ellis 2001), non-native speakers pay attention to single words and fail to notice the words with which they co-occur. The results of their study indicate that non-native speakers also retain words as they appear together, thus disproving Wray's claim. They argued that any collocation incompetence among non-native speakers is caused by inadequate input. Their results also indicate that fluency-oriented repetition of individual sentence contexts, as opposed to exposure to the same collocations in different contexts, has a positive effect on collocation learning. These findings were confirmed by Webb, Newton, and Chang (2013), whose study indicates that collocations may be learned incidentally and that the number of encounters (repetitions) has a positive effect on learning. This finding emphasizes the role of input before sizeable gains can be obtained.

The above studies discuss classroom practices aimed at helping learners notice collocations explicitly or implicitly in the hope that this will lead them to retaining them. Other studies have attempted to help learners notice collocations through an awareness-raising approach, while at the same time paying attention to learning processes. As opposed to the studies described so far, they try to involve the students in reflecting on their learning processes as part of awarenessraising, and are thus interested in learners' collocation-learning strategies. These studies include Barfield (2009), Peters (2009), and Ying and O’Neill (2009). Barfield (2009) and Ying and O'Neill (2009) examined the collocation practices of the students who participated in their studies, which aimed to understand the processes in which students engage while learning collocations and the strategies they use. Barfield (2009) and Ying and O'Neill (2009) refer to their strategy as a "process-oriented approach".

Barfield (2009) followed a group of learners for an academic year to trace what the learners did in their learning of collocations and how their strategies changed over time. Participants were introduced to the concept of collocations and shown how to make collocation notes. They were 
also asked to write reflections on the way in which they were recording collocations and to share their learning techniques with classmates in the form of interviews which were analysed later. Barfield (2009:211-212) points to five major trends in students' learning of collocations: "understanding and reconfiguring past vocabulary practices; interpreting different worlds of everyday use; moving from quantity of lexical knowledge to quality of collocation use; reconnecting what is known and projecting new identities; developing authorship".

Ying and O'Neill (2009) refer to their approach as AWARE, an acronym for the following steps of an awareness-raising approach to the teaching of collocations:

A: $\quad$ Awareness - raising of important language features, in particular collocations (helping learners notice collocations in the weekly theme-based readings or any other sources of input)

W: Why should we learn collocations? (helping learners see the rationale for/meaning of learning what they learn)

A: Acquiring noticed collocations using various strategies (learners making selective use of a repertoire of learning strategies that suit their individual learning style to promote effective learning of collocations)

R: $\quad$ Reflection on learning processes and content (learners thinking about their learning processes and making necessary adjustments for better learning)

E: $\quad$ Exhibiting what has been learned (learners making a weekly oral report in class on the theme under focus by using as many as possible of the collocations they have noticed and learned)

Ying and O’Neill (2009:183)

According to Ying and O'Neill (2009:184), this process-oriented learning approach rests upon two fundamental beliefs:

One is that learning will be more effective if learners are made aware of language and language learning at three levels: noticing the particular language features that they need to learn, developing an awareness of learning strategies, and a metacognitive awareness of reflecting on their learning process and content. The other central belief is that effective learning is more likely to take place when learners see the significance of learning what they learn and are given opportunities to exhibit what they have learned.

Students' reports as well as an analysis of their reflective journals showed that "collocation awareness could be successfully enhanced through pedagogical intervention" (Ying and O’Neill 2009:192).

Peters (2009) combined both performance and processes in her study by adopting a pre-/postexperimental design and by interviewing participants to inquire about their learning processes. Even though she did not find any significant difference in performance between the experimental and control group, she could gain insight into learners' processes in their learning of collocations. Interestingly, her study shows that both groups paid attention to collocations, even though the control group was asked to pay attention to individual words. The main reason for this is that participants in this study were advanced EFL learners of English, who said that they were interested in noticing collocations although they were not asked to. 
Overall, the awareness-raising approach has been positively assessed and could prove to be an efficient method for teaching collocations (Granger and Meunier 2008, Henriksen and Stoehr 2009, Nesi 2009). The effectiveness of 'phrase-noticing', an approach inspired by Lewis's Lexical Approach, has been put to the test by Boers et al. (2006) and Coxhead (2008), amongst others. Phrase-noticing rests on the same fundamental principle as the awareness-raising approach. It was however used in a more controlled experimental setup in a similar fashion to the studies described in the above paragraphs. Boers et al. (2006) measured possible gains in terms of participants' oral proficiency as a result of the phrase-noticing activities in which they had taken part. Boers et al. (2006) conclude that the phrase-noticing approach helped the students recognise collocations that they could use in real conversations, therefore improving their oral proficiency. Coxhead (2008) used the phrase-noticing approach and helped students notice common target collocations/phrases presented in reading texts. Participants were then given a limited time to write an essay and were interviewed regarding their vocabulary use. Gains in collocations were examined in the products of these two tests. All the participants reported having progressed in their knowledge of the phrases to which they had been exposed, lending support to the observed (see experimental studies above) or perceived (see awarenessraising studies above) gains in collocation knowledge resulting from the explicit teaching of collocations.

Other studies (although not many) have opted for the use of online tools. Sun and Wang (2003) explored the effectiveness of learning collocations using online concordancers. They found that the use of online concordancers resulted in significant gains in collocation knowledge. Chan and Liou (2005) also found online concordancers to be effective tools for teaching collocations; they were also positively assessed by participants in their study. Liu (2010) is another strong supporter of the use of corpora in the teaching of collocations. He negatively assesses the most commonly adopted teaching approaches, which he labels 'notice-memorise' approaches. Furthermore, he argues that the few studies that adopt a corpus approach to teaching collocations do not do enough, as they only help learners notice and identify collocations, without involving "any analysis of the reasons that words in collocations collocate the way they do" (Liu 2010:21-22), which could benefit learning.

A particularly interesting study on teaching collocations is Seesink (2007), which systematically selected collocations to teach from the AWL. This study adopted a blended learning approach, using both in-class and online activities in order to draw learners' attention to academic vocabulary and collocations in particular. In-class activities focused on different aspects of vocabulary, i.e. the syntactic category of words, word parts, dictionary definitions, and collocations, especially their role in L2 vocabulary development; while the online component provided a platform for reviewing and practising collocations. Although Seesink (2007) does not specifically state the approach adopted, it can be inferred that awareness-raising was at the centre of the activities in which she engaged her students. The study's results show that learners indeed used collocations following classroom instruction and online exercises. The main limitation of her study, however, is that she did not involve her participants in pre-/postintervention essay writing. The same goes for the control test administered at the end of the course, which shows that learners did well on collocations. The question that remains unanswered is the extent to which the intervention contributed, as she did not pre-test participants prior to the course. 
The present study supports the argument underlying the teaching of vocabulary with explicit focus on collocations. It is clear that teaching vocabulary through single words often leads to lexical incompetence, because learners have to learn later how to combine the words for productive purposes (Barfield 2009, Farghal and Obiedat 1995, Wray 2002). It takes up the idea of teaching collocations from the AWL in higher education (cf. Seesink 2007) and adopts the awareness-raising approach, with words presented to learners in a collocation web model (cf. Section 3.2).

From the studies reviewed in this section, it seems that the tendency is that studies adopting an explicit approach bring about more collocation gains. It would thus not be wrong to conclude that the calls to teach collocations explicitly are warranted. This study endorses the view that exposing learners to collocations explicitly or implicitly brings about collocation gains. In particular, progress has been made in terms of the positive effect the explicit teaching of collocations has on learners' retention. However, the question of which collocation should be given priority and which approach should be adopted remains unresolved (Granger and Meunier 2008, Webb and Kagimoto 2011, Nizonkiza and Van de Poel 2014). Furthermore, the formats currently in use seem to favour receptive approaches, and, as pointed out by Nation and Chung (2009), teaching receptively fosters growth of receptive but not productive knowledge. Therefore, more work needs to be done. Attempting a production-oriented approach may provide insight into the teaching and learning of collocations.

\section{The present study}

\subsection{Participants}

The target population of this study consisted of English majors enrolled in courses offered by the Department of English Language and Literature at the University of Burundi for the Bachelor of Arts (BA) degree. This used to be a four-year degree, but following a recent programme change (since the 2011-2012 academic year), the BA degree is now completed in three years. Participants $(\mathrm{N}=218)$ in this study were third-year students and were the last group following the four-year BA degree programme. All of them were Burundi nationals aged between 22 and 26 . They spoke four languages with varying degrees of proficiency. They were fluent speakers of Kirundi, their mother tongue; and French, an official language and language of education in Burundi. They also spoke Kiswahili, a lingua franca of the region; and English, a foreign language in Burundi, but the one in which they were majoring. Participants in this study were taught English as a subject from the second year of secondary school and had been exposed to it for six years before entering university. It is worth noting, however, that Burundi is reforming its education system, and English has been taught as a subject from the first grade of primary school onwards since 2007. Participants in this study did not have much exposure to English outside the classroom, through the internet and television, for example. Their proficiency level in English was not directly measured, but it could be estimated as low to upper intermediate based on previous studies (e.g., Nizonkiza 2012a), while their vocabulary size could be estimated at about 5,000 words (e.g., Nzambimana 2015).

\subsection{Course design}

For the purpose of this study, a collocation-based syllabus was developed and presented to participants as part of a writing course. The writing course is a four-credit course which has a 
twofold objective, namely writing an argumentative essay and building productive vocabulary by teaching collocations. The course consisted of a total of 60 hours, 20 of which were allocated to teaching and practising argumentative essay writing (introduction, body paragraphs, and conclusion), while 40 were allocated to the teaching of collocations. The collocation-based syllabus, which aimed to foster productive use of academic vocabulary, was designed using two sources. The AWL (Coxhead 2000) was used as a source for selecting target words, and the Oxford Collocations Dictionary for Students of English (Crowther et al. 2002) was used to select their collocations.

The Oxford Collocations Dictionary for Students of English (Crowther et al. 2002) is a collocation dictionary that was compiled based on the British National Corpus and is intended for teaching and learning purposes. This implies that the dictionary is designed as a learning tool, with authentic example sentences. The latter were selected from and presented as they appear in the British National Corpus or were slightly amended to facilitate students' comprehension. It also presents collocations following their syntactic categories and meanings in case of polysemous words.

The teaching method adopted is the awareness-raising approach (cf. Barfield 2009 among others), which suggests actively engaging participants in the teaching-learning process in order to raise their awareness of collocations. The latter was achieved in a seven-step process. First, students were required to identify all the nouns from the first three sub-lists of the AWL. A total of 131 nouns - 43 from the first sub-list, 45 from the second, and 43 from the third - were identified and cross-checked for accuracy with the help of the instructor. For example, analysis and approach come from sub-list one, while acquisition and alternative come from sub-lists two and three, respectively (see Appendix A for an exhaustive list of the nouns used in this study). Secondly, students $(\mathrm{N}=128)$ were divided into groups of 10 members each and then given words (approximately 10 nouns) to work on. Thirdly, they were instructed to look them up in the Oxford Collocations Dictionary for Students of English and select their collocations. As collocations of a noun are mainly adjectives and verbs in the verb-noun and noun-verb combinations, students were instructed to restrict their searches to these two types.

The learners then mapped their collocations onto a Collocation Web Model (see examples in Figures 1 and 2 below). The Collocation Web Model is an adapted version of McCarthy and O'Dell (2005). The original model suggests placing a target word at the centre of a word web model. The boxes of the model are each connected to the centre by means of lines. The boxes contain the definitions of the collocations, which learners are instructed to find. With this original model, L2/FL learners may understand the definitions, but they can still fail to find the appropriate word (Nizonkiza 2012a, Nizonkiza and Van de Poel 2014). This is why this model needs to be adapted. Nizonkiza (2012a) and Nizonkiza and Van de Poel (2014) argue that while this model may work for native speakers, its efficiency among L2/FL students may be questionable. They suggest presenting the target words and their collocations in a collocation web model following their syntactic categories and meanings, as exemplified in Figure 1 for the first meaning of issue and Figure 2 for its second meaning.

Fourthly, each group was given an opportunity to present to the rest of the class the results of their searches. At this stage, students presented and discussed adjective + noun (e.g., big/burning issue), verb + noun (e.g., raise/discuss issue) and noun + verb (e.g., issue arise/underlie something) collocations. Fifthly, students were asked to select all the related 
example sentences of the adjective + noun and verb + noun collocations as presented in the collocation dictionary and then present the results of their searches to the rest of the class. Then, students were asked to retain two of their verb + noun collocation example sentences per target word (noun), which they presented to the rest of the class in a similar fashion as in the previous step. This entails that students were expected to have mastered approximately 262 collocations (131 x 2) by the end of the course. Finally, students were given reinforcement exercises. The latter consisted of a sample of sentences from the previous step (selected from their presentations), which were gapped for the exercises.

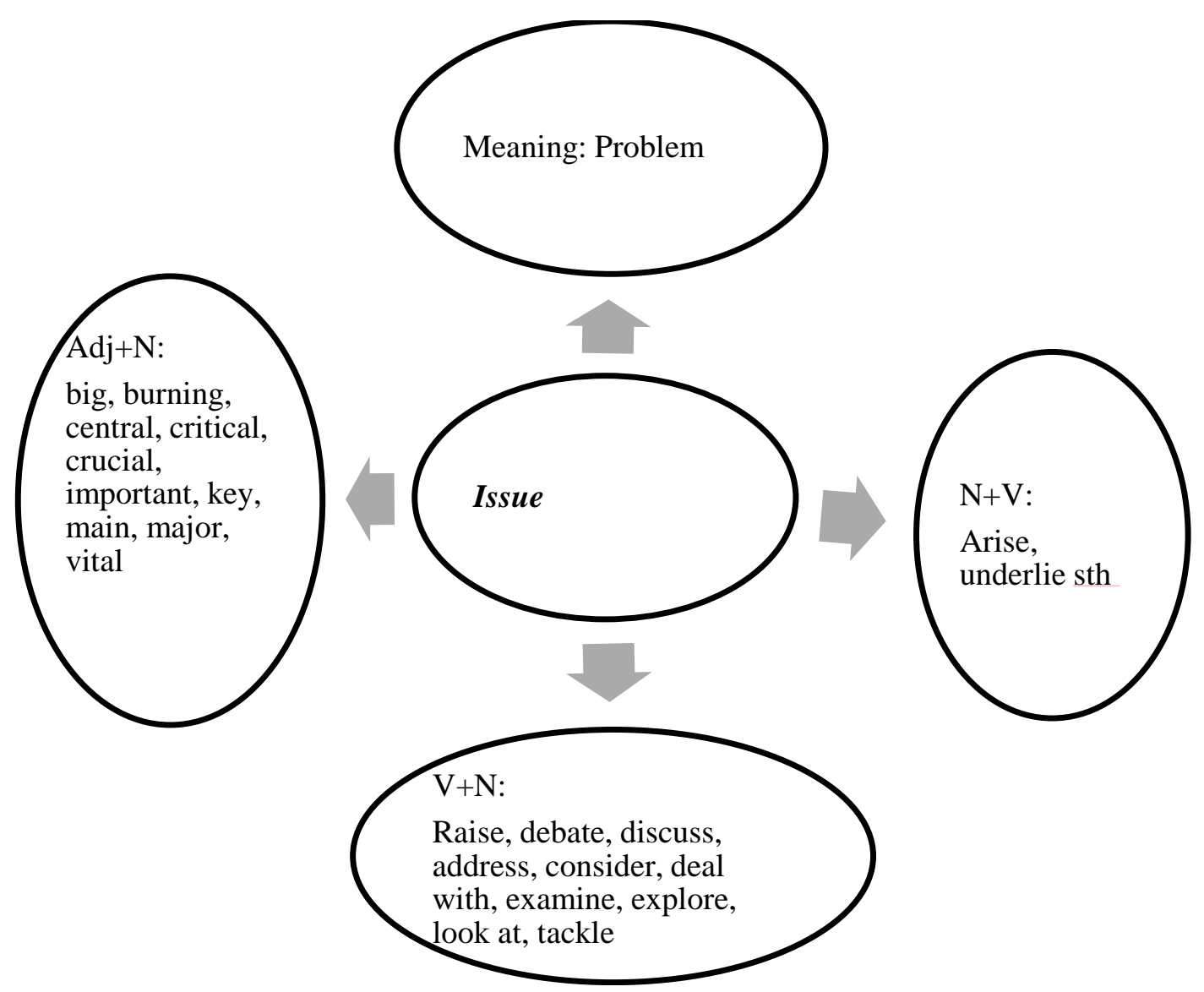

Figure 1: Issue (first meaning) mapped onto the collocation web model 


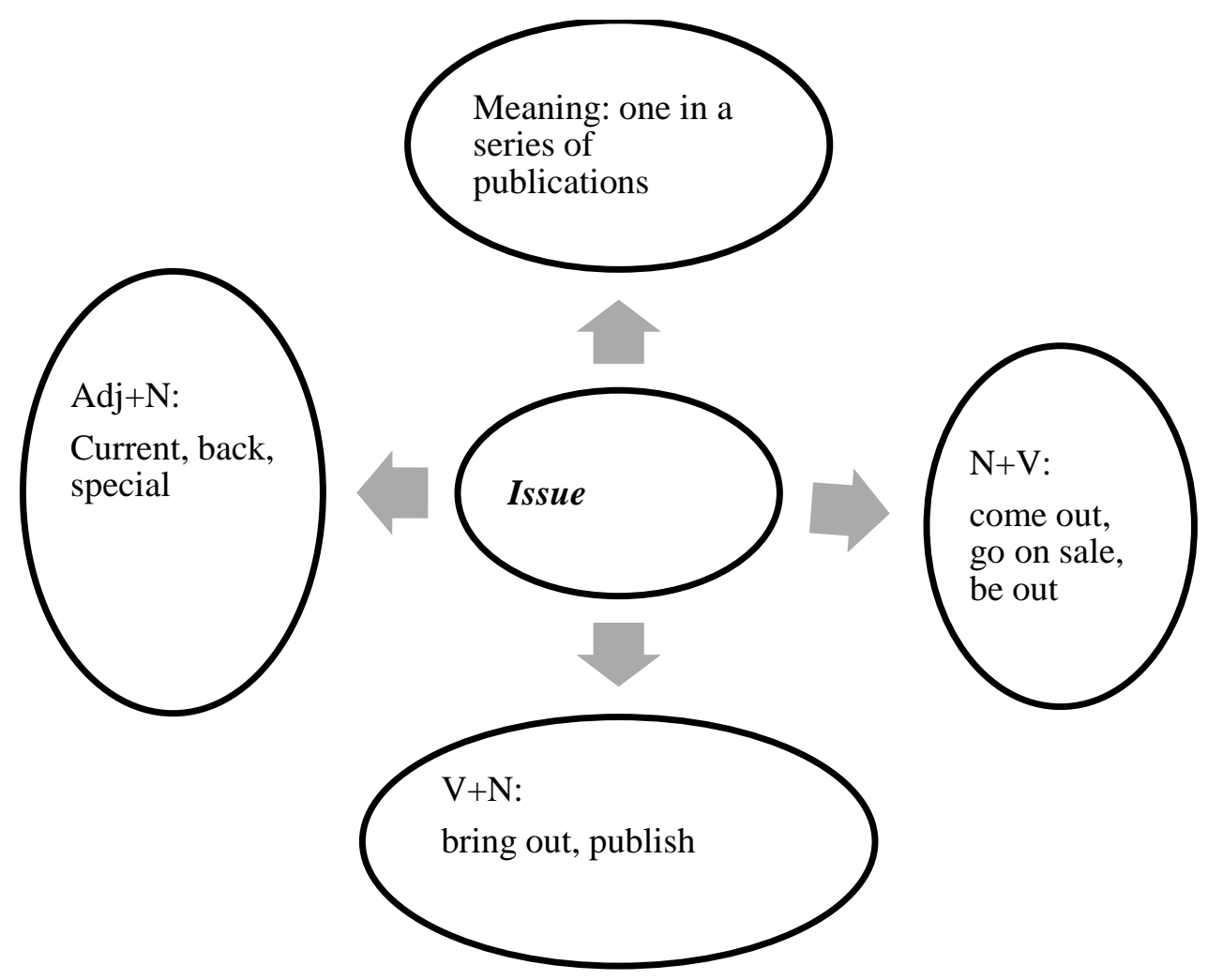

Figure 2: Issue (second meaning) mapped onto the collocation web model

As can be seen in Figure 1, syntactic categories enable learners to identify the appropriate combinations in English. Clearly, students can see that adjectives collocate with nouns in an adjective-noun combination (e.g. burning issue). They can also see that verbs collocate with nouns in a noun-verb combination (e.g. issue arise) and/or a verb-noun combination (e.g. raise issue). Regarding meanings, they dictate the collocates with which a given word combines of which learners should be aware. For instance, issue meaning "problem" (Figures 1) collocates with raise, debate, discuss, address, consider, deal with, examine, explore, look at, and tackle in the verb-noun combinations; while issue meaning "one in a series of publications" (Figures 2) collocates with bring out and publish in the verb-noun combination. Another obvious advantage of the collocation web model adopted in the present study is that collocational webs allow learners to create and recreate such webs in their minds, thus facilitating learning (Handl 2009). This approach is supported by Nation's (2001) principles that underlie the teaching of vocabulary, i.e. noticing, retrieving, and generating.

Collocations were noticed (noticing) as students responded to the instructions to (i) select collocations of the target words and map them onto the collocation web model, (ii) identify the example sentences provided in the dictionary for verb-noun and adjective-noun, and (iii) discuss them in groups. Each group had to present the example sentences to the rest of the class.

Retrieving and generating were practised through reinforcement exercises involving gapped sentences. The target nouns were embedded in a sentential context. The collocations (verbs) were deleted, and participants were instructed to supply them. In order to engage the learners, as suggested by Schmitt (2010), participants were informed that the collocations would be part of their assessment at the end of the course and would therefore count for the final mark of the 
writing course. The course lasted for two weeks and participants were tested at the end of the third week.

Verb + noun collocations were focused on in this study because "(a) they constitute frequent occurrences, (b) they are very difficult for L2 learners, and (c) they contain the most important information for communication" (Nizonkiza 2012b:74, quoting Gyllstad 2007). Furthermore, in order to justify the focus on verb + noun collocations, Nizonkiza (2012b:74) advances the argument that people tend to name things first (nouns) before naming how to do them (verbs). For these reasons, students were instructed to focus on the verb + noun collocations for the identification of example sentences, group discussions, presentations in class, and reinforcement exercises.

\subsection{Instruments}

\subsubsection{The collocation test}

Participants completed Nizonkiza's (2014) collocation test before and after the course. The test was developed with target words (nouns) selected from the AWL (Coxhead 2000) using a systematic random sampling technique (Babbie 1990). The sampling technique suggests selecting every $\mathrm{n}^{\text {th }}$ word from a random starting point. Six words were selected from each of the 10 sub-lists of which the AWL consists, with every $10^{\text {th }}$ word selected (each of the 10 sublists of the AWL except the $10^{\text {th }}$ consists of 60 words, which explains the sampling ratio of 10 ). It is worth noting that whenever the $10^{\text {th }}$ word was not a noun, the next word was selected instead. However, as the course focused on the first 3 sub-lists of the AWL, only the first 18 items (selected from these sub-lists) were retained for this study (see Appendix C).

For the reasons explained in section 3.2, verb-noun combinations were favoured and the collocations were selected from Crowther et al. (2002). The procedure was to look up the target word in the collocation dictionary under the verb-noun entry and then select its collocates (verbs) for which example sentences were provided. If many examples were given, the first one was retained. The test was modelled on Laufer and Nation's (1999) test. As Laufer and Nation suggest, only the first two letters of the collocates were provided. This is referred to as a "controlled productive knowledge test". Laufer and Nation (1999:37) define controlled knowledge as

the ability to use a word when compelled to do so by a teacher or researcher, whether in an unconstrained context such as a sentence writing task, or in a constrained context such as a fill in task where a sentence context is provided and the missing target word has to be supplied.

In line with Gyllstad's (2007) suggestion that collocates should not be less frequent than the target word (node), collocate frequencies were checked against Nation's (2006) frequency list. Most of the collocates were more frequent than the target words, and the few that were less frequent were replaced. The participant's task was to fill in the missing letters. An example was provided (see below). 
Instruction: Complete the underlined words in the sentences below.

Example: $\quad$ They ma........ a beautiful couple.

They make a beautiful couple.

As the test focuses on collocations, grammatical and spelling mistakes were not considered when marking. Participants were awarded one mark for a correct answer and zero marks for no or an incorrect answer. The test was graded out of 18 marks in total.

\subsubsection{The open writing task}

For the purpose of this study, students were given a writing task at the beginning (preintervention essay) and at the end (post-intervention essay) of the course. They were asked to write an argumentative essay of about 300 words on two topics deemed familiar to them. The pre-intervention essay was written on spending money on girls' education in Burundi, while the second was written on the English immersion programme for English majors which used to be organised at the end of their undergraduate studies and which had just been recalled. Like the collocation test, the post-intervention essay was presented as the final exam in the writing course. The pre-intervention essay was presented as one of the in-class assignments for the same course (at the beginning).

It is worth noting that in both sessions, a sample of 52 essays (about one third of the participants who completed both tasks) was selected for analysis, and only the introductory sections were analysed. The main reason for this is that students had been introduced to writing an argumentative essay in a writing course the previous year, but were not then instructed about presenting supporting details. The latter was the subject matter of the writing course they were following. Therefore, at the beginning of the writing course, students could only be assumed to know how to write an introduction, which motivated the choice. All the verb-noun combinations from the selected samples were identified and then weighed against Crowther et al.'s (2002) Oxford Collocations Dictionary for Students of English.

\section{Findings}

\subsection{Item description}

The test items were analysed in terms of their reliability, and Cronbach's Alpha was computed. The Alpha for the pre-test was 0.663 , while that of the post-test was 0.722 . In both sessions, the Alpha falls within the acceptable range of 0.7 (cf. Pallant 2007), and the test can thus be considered internally consistent. The items were analysed further in order to test their discriminatory power among test-takers. To this end, the corrected item-total correlation (CITC), which is measured on a scale of -1 to +1 and where a higher figure indicates better discriminatory ability, was calculated. It was further weighed against Ebel's (1979) scale, which distinguishes four categories of items: 0.40 and higher: definitely good items; 0.30 to 0.39 : reasonably good items; 0.20 to 0.29: marginal items in need of improvement; and below 0.19 (cut-off point): poor items, to be revised or eliminated. The results are presented in Table 1. 
Table 1: Corrected item-total correlation on Ebel's scale

\begin{tabular}{|l|l|l|l|l|}
\hline CITC & $\mathbf{0 . 4 0}$ and higher & $\mathbf{0 . 3 0}$ to 0.39 & $\mathbf{0 . 2 0}$ to 0.29 & Below 0.19 \\
\hline Item number pre-test & & $\begin{array}{l}3,5,7,12,15, \\
17\end{array}$ & $4,9,11,16$ & $\begin{array}{l}1,2,6,8, \\
10,13,14, \\
18\end{array}$ \\
\hline Total items & & $6(33.3 \%)$ & $4(22.2 \%)$ & $8(44.4 \%)$ \\
\hline $\begin{array}{l}\text { Item number post- } \\
\text { test }\end{array}$ & $4,6,10$ & $\begin{array}{l}2,3,11,13,16, \\
18\end{array}$ & $5,9,12,14,17$ & $1,7,8,15$ \\
\hline Total items & $3(16.6 \%)$ & $6(33.3 \%)$ & $5(27.7 \%)$ & $4(22.2 \%)$ \\
\hline
\end{tabular}

As can be seen in Table 1, 77.6\% of the items (14 items out of 18) function well for the posttest, with only 4 items $(22.2 \%)$ falling below the cut-off point. Overall, during the post-test session, the test worked well. The situation is different for the pre-test session, where there are twice as many items that fall below the cut-off point (44.4\%), but slightly over $50 \%$ of the items can be said to function well. Two reasons may account for the pre-test session's lower consistency. Either the items in the pre-test were too difficult for the students or the students did not take the test seriously, as it was administered on the first day of the course for research purposes and did not count for marks. During the course, however, students were informed that they were going to sit a collocation test that would be part of their assessment after the course and were given a week to prepare.

\subsection{Building productive academic vocabulary by teaching collocations}

The first question investigated in this study is whether explicitly teaching collocations can build productive academic vocabulary. This was tested by comparing participants' pre- and post-test scores on the collocation test and by running a paired sample t-test. The means and standard deviations are presented in Table 2. As can be seen, the mean is 7.70 for the pre-test session and 11.06 for the post-test session.

Table 2. Means of collocation pre-test and post-test scores compared

\begin{tabular}{|l|l|l|l|l|l|l|}
\hline \multicolumn{2}{|c|}{} & Mean & N & Std. Deviation & Gain & $\begin{array}{l}\text { Significance } \\
\text { (2-tailed) }\end{array}$ \\
\hline \multirow{2}{*}{$\begin{array}{l}\text { Test } \\
\text { scores }\end{array}$} & Pre-test score & 7.70 & 158 & 1.908 & 3.4 & 0.000 \\
\cline { 2 - 5 } & Post-test score & 11.06 & 158 & 2.921 & \\
\hline
\end{tabular}

These scores show that students achieved a better score on the post-test, with a fair gain of 3.4. This difference is statistically significant, meaning that participants performed significantly better on the post-test than on the pre-test $[\mathrm{t}(157)=14.04, p=0.000]$. This implies that teaching collocations explicitly contributes to their retention and therefore to building students' productive academic vocabulary. This gain in performance represents possible additions of collocations as a result of the intervention. These results indicate that teaching collocations could result in an improved use of them, thus building and improving students' productive academic vocabulary. This answers the first research question. 


\subsection{Teaching collocations improves students' writing}

The second research question investigated in this study is the extent to which teaching collocations improves the writing component of academic literacy. In order to answer this question, the verb-noun combinations identified from the sample of pre- and post-intervention essays were analysed and rated as 'correct' or 'incorrect' with reference to the Oxford Collocations Dictionary for Students of English (Crowther et al. 2002). The results of the analysis indicate that approximately 120 verb-noun combinations were used in the preintervention essays. Of these, 56.6\% (68) were correctly used, and $43.3 \%$ (52) were incorrectly used. An analysis of the post-intervention essays reveals that a total of 182 verb-noun combinations were used: $64.1 \%$ of the combinations (118) were used correctly, while $35.1 \%$ (64) were used incorrectly.

Considering the proportions of correct/incorrect collocations in the two writing tasks, it is clear that students used more correct collocations in the post-intervention essay. The collocation use in both sessions was compared by running a paired sample t-test, which shows that, on average, a student produced 1.31 correct collocations in the pre-intervention essay and 2.27 correct collocations in the post-intervention essay (cf. Table 3).

Table 3. Pre-intervention and post-intervention collocation use compared

\begin{tabular}{|l|l|l|l|l|l|l|}
\hline \multicolumn{2}{|c|}{} & Mean & N & Std. Deviation & Gain & $\begin{array}{l}\text { Significance } \\
\text { (2-tailed) }\end{array}$ \\
\hline \multirow{2}{*}{$\begin{array}{l}\text { Essay } \\
\text { scores }\end{array}$} & Pre-intervention & 1.31 & 52 & 1.213 & .962 & .002 \\
\cline { 2 - 5 } & Post-intervention & 2.27 & 52 & 1.880 & & \\
\hline
\end{tabular}

This gain of approximately one collocation on average, as small as it may seem, is statistically significant $[\mathrm{t}(51)=3.30, p=0.002]$. What we learn from these findings is that, in this study, the significant gains observed between the pre- and post-intervention tests indicate that the teaching of collocations may result in their being used more accurately. These findings answer the second research question addressed in this study, regarding whether teaching collocations can bring about an improvement in the use of collocations in students' written production.

\section{Discussion and conclusion}

The present study examined the issue of teaching collocations of words drawn from the AWL and its possible contribution to building academic vocabulary and improving EFL higher education students' written output. The first question was answered by administering a collocation test in a pre-/post-experimental setup involving students taking a writing course at a university in Burundi. A comparison of the pre- and post-test scores shows that performance is better on the post-test, which suggests that the intervention led to measurable improvements.

The second question was answered by comparing the same participants' pre- and postintervention course sample essays. The results indicate that students used significantly more collocations in the post-intervention essay. This improved performance in terms of collocation use can be attributed to the intervention that was conducted, which implies that teaching collocations explicitly in a writing course is likely to improve students' written output. 
These results corroborate previous findings that raising students' awareness of collocations results in improved mastery of them (cf. Barfield 2009, Boers and Lindstromberg 2008, Boers and Lindstromberg 2009, Boers et al. 2006, Boers et al. 2012, Boers et al. 2014, Coxhead 2008, Jiang 2009, Sonbul and Schmitt 2013, Wray and Fitzpatrick 2008, Ying and O'Neill 2009). This extends to collocations pertaining to the AWL. It particularly complements Seesink (2007), which shows that raising L2 learners' awareness of collocations from the AWL leads to correct use of them. A shortcoming of Seesink (2007) is that it does not show the extent of this improvement. The present study complements Seesink (2007) by pointing to measurable improvements in both controlled and uncontrolled settings. In Nizonkiza's (2012b) terms, the mean difference between post-test and pre-test scores on a collocation test gives an indication of collocations that learners can add to their repertoire as a result of intervention.

The pedagogical consequence that arises from these findings is that intervention with a particular focus on collocations from the AWL could contribute towards building the vocabulary needed in academic settings and using it efficiently. This is to say that explicitly teaching collocations results in their improved use. This is likely to improve the writing component of participants' academic literacy, which in Weideman's (2007) terms refers to building an academic vocabulary and producing good written output. Given the widely accepted role of collocations in academic texts (Gledhill 2000) and that intervention may result in improvements, I argue strongly in favour of teaching collocations of words from the AWL as part of academic literacy modules. This, I believe, will help develop students' academic literacy, particularly the writing component thereof.

However, as the present study is exploratory in nature, results should be generalised with caution. Indeed, research evidence has shown that growth of collocational knowledge takes time (Gyllstad 2007, Shillaw 2009, Li and Schmitt 2009), and participants in this study did not sit a delayed test (be it controlled or otherwise). Therefore, the study gives an indication that raising students' awareness has a positive effect on collocation retention and use. It remains to be seen, however, whether students will be able to recall and correctly use these collocations in the long run. Not administering a delayed test to participants is one of the limitations of this study. Another major limitation is that no control group was involved. It is therefore not known whether the collocation gains could be attributed to the learning conditions, to outside learning, or to a testing effect. Furthermore, participants' overall proficiency and vocabulary size were assumed but not measured. Given that research evidence indicates that these factors may influence students' use of collocations, this is yet another major limitation of the study. To address these limitations, this study is being replicated, which will hopefully shed more light on this issue.

As discussed above, despite its limitations, the present study's results suggest that teaching collocations explicitly (through the awareness-raising approach operationalised by means of a collocation web model) may lead to their retention and effective use. This suggests that students' writing can be improved by teaching collocations. These findings answer the fundamental questions examined in this study, but at the same time, the study raises other questions worth examining further in follow-up studies.

First of all, the study's participants formed a homogenous group, as they belonged to the same class. It would be interesting to involve more participants, ideally with different levels of proficiency, and then test whether improvements result at different learning stages. Secondly, 
the study only investigated verb-noun combinations. The question arises whether other types of collocations would behave in the same way. This needs to be investigated in a follow-up study. Thirdly, while the awareness-raising approach adopted in this study has been used in other studies, whose results also suggest that it brings about improvements, the collocation web model with which it was used in the present study has not yet been tested in other studies. I therefore suggest testing the model and comparing the results with (an)other model(s) and assessing the extent to which it works. Finally, the present study was interested in one aspect of academic literacy, i.e. the writing component. Follow-up studies could involve other components such as reading, which may provide more insight into the development of academic literacy.

Overall, the present study has demonstrated that raising students' awareness of collocations may result in building academic vocabulary, which they can to some extent use. This study therefore suggests including collocations, especially of words selected from the AWL, in course modules aimed at teaching academic literacy. This may lead to improving the writing component of academic literacy. It is hoped that this study contributes to the existing body of literature in this field and takes the debate on how to improve academic literacy a step further.

\section{References}

Babbie, E.R. 1990. Survey research methods. California and Belmont: Wordsworth Company.

Barfield, A. 2009. Following individual L2 collocation development over time. In A. Barfield and H. Gyllstad (eds.) Researching collocations in another language. New York: Palgrave Macmillan. pp. 208-223.

Barfield, A. and H. Gyllstad (eds). 2009. Researching collocations in another language. New York: Palgrave Macmillan.

Boers, F. and S. Lindstromberg (eds.) 2008. Cognitive approaches to teaching vocabulary and phraseology. Berlin: Mouton De Gruyter.

Boers, F. and S. Lindstromberg. 2009. Optimizing a lexical approach to instructed language acquisition. New York: Palgrave Macmillan.

Boers, F., M. Demecheleer, A. Coxhead and S. Webb. 2014. Gauging the effects of exercises on verb-noun collocations. TESOL 18(1): 54-74. doi:10.1177/1362168813505389

Boers, F., T.C.T. Dang and S. Brian. 2016. Comparing the effectiveness of phrase-focused exercises: A partial replication of Boers, Demecheleer, Coxhead, and Webb (2014). Language Teaching Research 21(3): 362-380. doi:10.1177/1362168816651464

Boers, F., J. Eyckmans, J. Kappel, H. Stengers and M. Demecheleer. 2006. Formulaic sequences and perceived oral proficiency: Putting the Lexical Approach to the test. Language Teaching Research 10(3): 245-261. doi:10.1191/13621688061r195oa 
Boers, F., S. Lindstromberg and J. Eyckmans. 2012. Are alliterative word combinations comparatively easy to remember for adult learners? RELC Journal 43(1): 127-135. doi:10.1177/0033688212439997

Bonk, W.J. 2001. Testing ESL learners' knowledge of collocations. In T. Hudson and J.D. Brown (eds.) A focus on language test development: Expanding the language proficiency construct across a variety of tests. Honolulu: University of Hawaii Second Language Teaching and Curriculum Center. pp. 113-142.

Braine, G. 2002. Academic literacy and the nonnative speaker graduate student. Journal of English for Academic Purposes 1(1): 59-68. doi:10.1016/s1475-1585(02)00006-1

Butler, G. 2013. Discipline-specific versus generic academic literacy intervention for university education: An issue of impact? Journal for Language Teaching 47(2): 71-88. doi:10.4314/jlt.v47i2.4

Chan, T.P. and H.C. Liou. 2005. Effects of web-based concordancing instruction on EFL students' learning of verb-noun collocations. Computer Assisted Language Learning 18(3): 231-51. doi:10.1080/09588220500185769

Cliff, A.F. and N. Yeld. 2006. Test domains and constructs: Academic Literacy. In H. Griesel (ed.) Access and entry level benchmarks: The National Benchmark Tests Project. Pretoria: Higher Education South Africa. pp. 19-27.

Coxhead, A. 2000. A new academic word list. TESOL Quarterly 34(2): 213-239. doi: $10.2307 / 3587951$

Coxhead, A. 2008. Phraseology and English for academic purposes: Challenges and opportunities. In S. Granger and F. Meunier (eds.) Phraseology. An interdisciplinary perspective. Amsterdam: John Benjamins Publishing Company. pp. 149-161.

Coxhead, A. 2011. The Academic Word List 10 years on: Research and teaching implications. TESOL Quarterly 45: 355-362. doi:10.5054/tq.2011.254528

Crowther, J., S. Dignen and D. Lea (Eds). 2002. Oxford collocations dictionary for students of English. Oxford: Oxford University Press.

Durrant, P. 2009. Investigating the viability of a collocation list for students of English for academic purposes. English for Specific Purposes 28: 157-169. doi:10.1016/j.esp.2009.02.002

Durrant, P. 2014. Discipline and level specificity in university students' written vocabulary. Applied Linguistics 35: 1-30. doi:10.1093/applin/amt016

Durrant, P. and N. Schmitt. 2010. Adult learners' retention of collocations from exposure. Second Language Research 26(2):163-188. doi:10.1177/0267658309349431

Ebel, R.L. 1979. Essentials of education measurement. New Jersey: Prentice Hall. 
Ellis, N.C. 2001. Memory for language. In P. Robinson (ed.) Cognition and second language instruction. Cambridge: Cambridge University Press.

Eyckmans, J. 2009. Toward an assessment of learners' receptive and productive syntagmatic knowledge. In A. Barfield and H. Gyllstad (eds.) Researching collocations in another language. New York: Palgrave Macmillan. pp. 139-152.

Farghal, M. and H. Obiedat. 1995. Collocations: A neglected variable in EFL. International Journal of Applied Linguistics 33(4): 315-332. doi:10.1515/iral.1995.33.4.315

Gitsaki, C. 1999. Second language lexical acquisition: A study of the development of collocational knowledge. San Francisco: International Scholars Publications.

Gledhill, C.J. 2000. Collocations in science writing. Tubingen: Gunter Narr Verlag.

Gouverneur, C. 2008. The phraseological patterns of high-frequency verbs in advanced English for general purposes: A corpus-driven approach to EFL textbook analysis. In F. Meunier and S. Granger (eds.) Phraseology in foreign language learning and teaching. Amsterdam: John Benjamins Publishing Company. pp. 223-243.

Granger, S. and F. Meunier (eds.) 2008. Phraseology. An interdisciplinary perspective. Amsterdam: John Benjamins Publishing Company.

Gyllstad, H. 2007. Testing English collocations. Doctoral dissertation. Lund: Lund University.

Handl, S. 2009. Towards collocational webs for presenting collocations in learners' dictionaries. In A. Barfield and H. Gyllstad (eds.) Researching collocations in another language. New York: Palgrave Macmillan. pp. 69-85.

Henriksen, B. and L.S. Stoehr. 2009. Processes in the development of L2 collocational knowledge: A challenge for language learners, researchers and teachers. In A. Barfield and $\mathrm{H}$. Gyllstad (eds.) Researching collocations in another language. New York: Palgrave Macmillan. pp. 224-231.

Howarth, P. 1998. Phraseology and second language proficiency. Applied Linguistics 19(1): 24-44. doi:10.1093/applin/19.1.24

Hyland, K. and P. Tse. 2007. Is there an "academic vocabulary"? TESOL Quarterly 41(2): 235253. doi:10.1002/j.1545-7249.2007.tb00058.x

Jaén, M.M. 2007. A corpus-driven design of a test for assessing the ESL collocational competence of university students. International Journal of English Studies 7(2): 127-147.

Jiang, J. 2009. Designing pedagogic materials to improve awareness and productive use of L2 collocations. In A. Barfield and H. Gyllstad (eds.) Researching collocations in another language. New York: Palgrave Macmillan. pp. 99-113. 
Kostogriz, A. and A. Godley. 2007. The construction of academic literacy and difference. English Teaching: Practice and Critique 6(2): 1-7.

Laufer, B. and N. Girsai. 2008. Form-focused instruction in second language vocabulary learning: A case for contrastive analysis and translation. Applied Linguistics 29(4): 694-716. doi:10.1093/applin/amn018

Laufer, B. and P. Nation. 1999. A vocabulary size test of controlled productive ability. Language Testing 16(1): 33-51. doi:10.1177/026553229901600103

Laufer, B. and T. Waldman. 2011. Verb-noun collocations in second language writing: A corpus analysis of learners' English. Language Learning 61(2): 647-672. doi:10.1111/j.1467$\underline{9922.2010 .00621 . \mathrm{x}}$

Lea, M.R. and B.V. Street. 1998. Student writing in higher education: An academic literacies approach. Studies in Higher Education 23(2): 57-173. doi:10.1080/03075079812331380364

Leki, I. 2000. Writing, literacy, and applied linguistics. Annual Review of Applied Linguistics 20: 99-115. doi:10.1017/s0267190500200068

Lewis, M. 1993. The Lexical Approach: The state of ELT and the way forward. Hove: Language Teaching Publications.

Lewis, M. 1997. Implementing the Lexical Approach: Putting theory into practice. Hove: Language Teaching Publications.

Lewis, M. 2000. Teaching collocations: Further development in the Lexical Approach. Hove: Language Teaching Publications.

Li, J. and N. Schmitt. 2009. The acquisition of lexical phrases in academic writing: A longitudinal case study. Journal of Second Language Writing 18(2): 85-102. doi:10.1016/j.jslw.2009.02.001

Liu, D. 2010. Going beyond patterns: Involving cognitive analysis in the learning of collocations. TESOL Quarterly 44(1): 4-30. doi:10.5054/tq.2010.214046

Meunier, F. and S. Granger (eds.) 2008. Phraseology in foreign language learning and teaching. Amsterdam: John Benjamins.

McCarthy, M. and F. O'Dell. 2005. English collocations in use. Cambridge: Cambridge University Press.

Nadarajan, S. 2011. The challenges of getting L2 learners to use academic words in their writings. Electronic Journal of Foreign Language Teaching 8(2): 184-200.

Nation, P. 2001. Learning vocabulary in another language. Cambridge: Cambridge University Press. 
Nation, P. 2006. How large a vocabulary is needed for reading and listening? Canadian Modern Language Review 63(1): 59-82. doi:10.3138/cmlr.63.1.59

Nation, P. and T. Chung. 2009. Teaching and testing vocabulary. In M.H. Long and C. Doughty (eds.) The handbook of language teaching. Malden: Wiley-Blackwell. pp. 543-559.

Nesi, H. 2009. Exploring materials for the study of L2 collocations. In A. Barfield and H. Gyllstad (eds.) Researching collocations in another language. New York: Palgrave Macmillan. pp. 114-124.

Nesselhauf, N. 2005. Collocations in a learner corpus. Amsterdam: John Benjamins Publishing Company.

Nizonkiza, D. 2012a. The relationship between lexical competence, collocational competence, and second language proficiency. Doctoral dissertation. Antwerp: University of Antwerp.

Nizonkiza, D. 2012b. Quantifying controlled productive knowledge of collocations across proficiency and word frequency levels. Studies in Second Language Learning and Teaching 2/1: 67-92. doi:10.14746/ssllt.2012.2.1.4

Nizonkiza, D. 2014. The relationship between productive knowledge of collocations and academic literacy among tertiary level learners. Journal for Language Teaching 48(1): 149171. doi:10.4314/jlt.v48i1.8

Nizonkiza, D. 2016. First-year university students' receptive and productive use of academic vocabulary. Stellenbosch Papers in Linguistics 45: 169-187. doi:10.5774/45-0-215

Nizonkiza, D. and K. Van de Poel. 2014. Teachability of collocations: The role of word frequency counts. Southern African Linguistics and Applied Language Studies 32(1): 301-316. doi:10.2989/16073614.2014.997061

Nizonkiza, D. and T. Van Dyk. 2015. Academic literacy of South African higher education level students: Does vocabulary size matter? Stellenbosch Papers in Linguistics 44: 147-174. doi: $10.5774 / 44-0-159$

Nzambimana, N. 2015. Relationship between vocabulary size and overall proficiency: The case of English majors at the University of Burundi. BA thesis. Bujumbura: University of Burundi.

Pallant, J. 2007. SPSS survival manual. Buckingham and Philadelphia: Open University Press.

Paquot, M. 2008. Exemplification in learner writing: A cross-linguistic perspective. In S. Granger and F. Meunier (eds.) Phraseology in foreign language learning and teaching. Amsterdam: John Benjamins Publishing Company. pp. 101-119.

Pawley, A. and F.H. Syder. 1983. Two puzzles for linguistic theory: Nativelike selection and nativelike fluency. In J.C. Richards and R.W. Schmidt (eds.) Language and communication. London: Longman. pp. 191-227. 
Peters, E. 2009. Learning collocations through attention-drawing techniques: A qualitative and quantitative analysis. In A. Barfield and H. Gyllstad (eds.) Researching collocations in another language. New York: Palgrave Macmillan. pp. 194-207.

Schmitt, N. 1998. Measuring collocational knowledge: Key issues and an experimental assessment procedure. ITL Review of Applied Linguistics 119-120: 27-47. doi:10.1075/itl.119$\underline{120.03 \mathrm{sch}}$

Schmitt, N. 2010. Researching vocabulary: A vocabulary research manual. Basingstoke and New York: Palgrave Macmillan.

Scholtz, D. 2012. Using the National Benchmark Tests in engineering diplomas: Revisiting generic academic literacy. Journal for Language Teaching 46(1): 46-58. doi:10.4314/jlt.v46i1.3

Seesink, M.T.D.N. 2007. Using blended instruction to teach academic vocabulary collocations: A case study. Doctoral dissertation. Morgantown: West Virginia University.

Shillaw, J. 2009. Developing and validating tests of L2 collocation knowledge. In A. Barfield and H. Gyllstad (eds.) Researching collocations in another language. New York: Palgrave Macmillan. pp. 171-180.

Schmitt, N. and D. Schmitt. 2005. Focus on vocabulary: Mastering the Academic Word List. London: Longman.

Sinclair, J. 1991. Corpus, concordance, collocation. Oxford: Oxford University Press.

Sonbul, S. and N. Schmitt. 2013. Explicit and implicit lexical knowledge: Acquisition of collocations under different input conditions. Language Learning 63(1): 121-159. doi:10.1111/j.1467-9922.2012.00730.x

Sun, Y.C. and L.Y. Wang. 2003. Concordancers in the EFL classroom: Cognitive approaches and collocation difficulty. Computer Assisted Language Learning 16(1): 83-94. $\underline{\text { doi: } 10.1076 / \text { call.16.1.83.15528 }}$

Van de Poel, K. and T. Van Dyk. 2014. Discipline-specific academic literacy and academic integration. In R. Wilkinson and M.L. Walsh (eds.) Integrating content and language in higher education: From theory to practice. Frankfurt am Main: Peter Lang. pp. 162-179.

Van der Walt, J.L. (ed.) 2011. Basic skills in academic literacy. Noordbrug: AndCork.

Van Dyk, T. 2005. Towards providing effective academic literacy intervention. Per Linguam 21(2): 35-51. doi:10.5785/21-2-75

Van Dyk, T. and K. Van de Poel. 2013. Towards a responsible agenda for academic literacy: Considerations that will benefit students and society. Journal for Language Teaching 47(2): 43-70. doi:10.4314/jlt.v47i2.3 
Van Dyk, T. and A. Weideman. 2004. Switching constructs: On the selection of an appropriate blueprint for academic literacy. Journal for Language Teaching 38(1): 1-13. doi:10.4314/jlt.v38i1.6024

Van Rooy, B. and S. Coetzee-Van Rooy. 2015. The language issue and academic performance at a South African University. Southern African Linguistics and Applied Language Studies 33(1): 31-46. doi:10.2989/16073614.2015.1012691

Wray, A. 2000. Formulaic sequences in second language teaching: Principle and practice. Applied Linguistics 21(4): 463-489.

Webb, S. and E. Kagimoto. 2009. The effects of vocabulary learning on collocation and meaning. TESOL Quarterly 43(1): 55-75. doi:10.1002/j.1545-7249.2009.tb00227.x

Webb, S. and E. Kagimoto. 2011. Learning collocations: Do the number of collocates, position of the node word, and synonymy affect learning? Applied Linguistics 32(3): 259-276. doi:10.1093/applin/amq051

Webb, S., J. Newton and A.C.S. Chang. 2013. Incidental learning of collocation. Language Learning 63(1): 91-120. doi:10.1111/j.1467-9922.2012.00729.x

Weideman, A. 2006. Assessing academic literacy in a task-based approach. Language Matters 37(1): 81-101. doi:10.1080/10228190608566253

Weideman, A. 2007. Academic literacy: Prepare to learn. Pretoria: Van Schaik Publishers.

Wray, A. 2002. Formulaic language and the lexicon. Cambridge: Cambridge University Press.

Wray, A. and T. Fitzpatrick. 2008. Why can't you just leave it alone? Deviations from memorized language as a gauge of nativelike competence. In S. Granger and F. Meunier (eds.) Phraseology. An interdisciplinary perspective. Amsterdam: John Benjamins Publishing Company. pp. 123-147.

Ying, Y. and M. O'Neill. 2009. Collocation learning through an 'AWARE' approach: Learner perspectives and learning process. In A. Barfield and H. Gyllstad (eds.) Researching collocations in another language. New York: Palgrave Macmillan. pp. 181-193. 


\section{Appendix A: Nouns Taught}

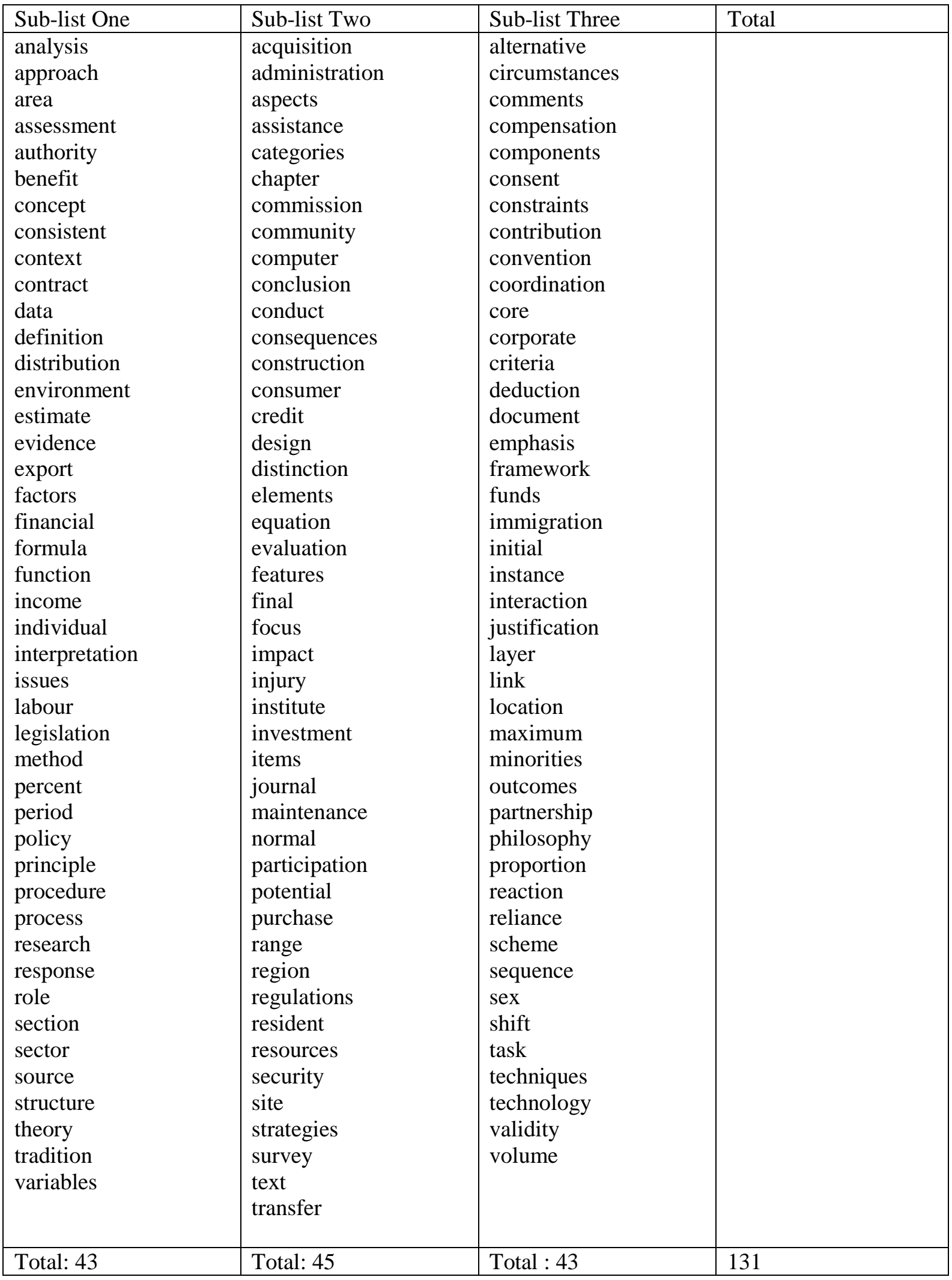




\section{Appendix B: Collocation test}

Name:

Native language:

Level of study (year):

Faculty:

University:
Date:

Start hour:

End hour:

Instruction: Complete the underlined words in the sentences below.

Example: $\quad$ They ma........ a beautiful couple.

They make a beautiful couple.

1. Villagers get together every year to ke............ this old tradition alive.

2. Institutions have to ex............. appropriate contexts in which to present examples of language in use for the children.

3. In order to fight against terrorism, the UN agreed on plans to res........... the export of arms to certain countries.

4. This evening, we need to ad............. the issue of legalisation of soft drugs.

5. She went on to ex............. the principle behind what she was doing.

6. We have to con............. many aspects of pollution in order to better tackle it.

7. If you do not have a regular income, you may be unable to ob............ credit.

8. It is difficult to ju............. the impact of the changes on employment patterns.

9. The latest developments will hardly af............ the perception of the crisis by the public.

10. The family will es............. temporary residence in the manor house.

11. They had to pe............. an in-depth analysis of the results.

12. Investigators are likely to $\mathrm{ad} . . . . . . . . . .$. a set of theories about the princess's death.

13. The school planned to in............. comments from parents about the new curriculum.

14. We must make a real effort to pr............. cooperation between universities and industry.

15. They have to of............. a basic framework of ground rules for discussions.

16. Use enough gravel to fo............ a layer about $50 \mathrm{~mm}$ thick.

17. The food shortage is likely to re............. crisis proportion.

18. She failed to co............ the task she had been set. 